\title{
Genetic influence of cytokine polymorphisms on the clinical outcome of Japanese gastrointestinal cancer patients in palliative care
}

\author{
ASAHI HISHIDA ${ }^{1}$, YOSHINAGA OKUGAWA ${ }^{2-4}$, YUHKI MORIMOTO ${ }^{2}$, \\ YUMIKO SHIRAI $^{5}$, KYOKO OKAMOTO ${ }^{6}$, SACHIKO MOMOKITA $^{4}$, AKI OGAWA ${ }^{6}$, KOJI TANAKA ${ }^{2,7}$, \\ RYUTARO NISHIKAWA ${ }^{2}$, YUJI TOIYAMA ${ }^{7}$, YASUHIRO INOUE ${ }^{7}$, HIROYUKI SAKURAI $^{8}$, \\ HISASHI URATA ${ }^{2}$, MOTOYOSHI TANAKA ${ }^{3}$, DONALD C. McMILLAN ${ }^{9}$ and CHIKAO MIKI ${ }^{2,7}$ \\ ${ }^{1}$ Department of Preventive Medicine, Nagoya University Graduate School of Medicine, Nagoya, \\ Aichi 466-8550; Departments of ${ }^{2}$ Surgery, ${ }^{3}$ Medical Oncology, ${ }^{4}$ Biochemical Laboratory, ${ }^{5}$ Nutrition and \\ ${ }^{6}$ Nursing, Iga City General Hospital, Iga, Mie 518-0823; ${ }^{7}$ Department of Gastrointestinal and Pediatric Surgery, \\ Division of Reparative Medicine, Institute of Life Sciences, ${ }^{8}$ Hepatobiliary Pancreatic and Transplant Surgery, \\ Mie University Graduate School of Medicine, Tsu, Mie 514-8507, Japan; ${ }^{9}$ Department of Surgical Science, \\ University of Glasgow School of Medicine, Dentistry and Nursing, Glasgow G4 0SF, UK
}

Received August 10, 2017; Accepted October 23, 2018

DOI: $10.3892 / \mathrm{ol} .2018 .9614$

\begin{abstract}
Gastrointestinal cancer is one of the most common causes of mortality globally. The present study examined the influence of cytokine genetic polymorphisms [interleukin $(I L)-1 B$ C-31T, $I L-1 R N$ VNTR, $I L-6$ C-634G, $I L-8 \mathrm{~T}-251 \mathrm{~A}, I L-10 \mathrm{~T}-819 \mathrm{C}$ and $I L-10 \mathrm{~A}-1082 \mathrm{G}]$ on clinical outcomes in patients with gastrointestinal cancer in palliative care. A total of 59 patients with gastrointestinal cancer who were admitted to Iga City General Hospital were analyzed. Genotyping was conducted using a polymerase chain reaction with confronting two-pair primers. Patients with at least one $I L-I R N 2$ allele demonstrated a significantly better survival $(\mathrm{P}=0.0275)$ while those with $I L-6-634 G / G$ demonstrated a worse survival $(\mathrm{P}=0.0024)$. Multivariate analyses using the Cox proportional hazard model revealed that those with at least one $I L-1 R N 2$ allele, $I L-6-634 G / G$ or $I L-10-1082 \mathrm{~A} / \mathrm{G}$ had a significantly elevated adjusted hazard ratio of $9.20(\mathrm{P}=0.014), 41.01(\mathrm{P}=0.001)$ or $6.49(\mathrm{P}=0.046)$, respectively, compared with those with each homozygous wild-type polymorphism. In addition, the evaluation of weight loss by genotype revealed the potential influence of $I L-10 \mathrm{~T}-819 \mathrm{C}$ genotype $(\mathrm{P}=0.072) . I L-I R N, I L-6$ and
\end{abstract}

Correspondence to: Dr Asahi Hishida, Department of Preventive Medicine, Nagoya University Graduate School of Medicine, 65 Tsurumai-cho, Showa-ku, Nagoya, Aichi 466-8550, Japan

E-mail: a-hishi@med.nagoya-u.ac.jp

Key words: cytokines, single nucleotide polymorphisms, cancer palliative care
IL-10 polymorphisms were associated with the survival of patients with gastrointestinal cancer, suggesting the clinical feasibility of genetic testing in patients with gastrointestinal cancer in palliative care.

\section{Introduction}

Gastrointestinal cancer is one of the most common causes of death worldwide. Many patients remain incurable mainly because the disease is detected late, thus requiring palliative medical care. Some of the most important factors to be considered are patients' nutritional status including weight loss, muscle wasting known as sarcopenia, and inflammation (1). Systemic inflammation that results from the tumor existence and progression has been shown to play key roles in these adverse effects, and recent studies have suggested that some genetic polymorphisms involved in immune or inflammatory processes may have an influence on patient outcomes, such as weight loss or survival, through the modulation of these pathways $(2,3)$. Our research group has reported the essential roles of interleukin (IL)-1B, IL-1RN, IL-6, IL-8 and IL-10 in human gastrointestinal cancers, underscoring the importance of these cytokines in the etiology of gastrointestinal cancers and subsequent systemic reactions (4-6). One rural hospital in central Japan, Iga General Hospital in the town of Ninja, provides palliative care including nutritional intervention for such patients with gastrointestinal cancers, and this hospital has accumulated considerable amounts of clinical data since the establishment of an outpatient clinic for cancer chemotherapy and palliative care in 2011. Here, we analyzed the body composition of almost all of the cancer patients who visited this clinic monthly, using the body composition measurement machine, InBody ${ }^{\circledR}$ (https:// inbodyusa.com/). Our aim was to evaluate the patients' 
health conditions including nutritional status to provide more effective palliative care, including nutritional interventions. In this study, we used clinical data from Iga General Hospital to examine the influence of genetic cytokine polymorphisms $[I L-1 B$ C-31T, $I L-1 R N$ variable number tandem repeats (VNTR), IL-6 C-634G, IL-8 T-251A, IL-10 T-819C, and $I L-10$ A-1082G] on clinical outcomes of the gastrointestinal cancer patients, to determine how to establish personalized palliative care for gastrointestinal cancer patients based on genetic information.

\section{Materials and methods}

Patients and samples. Data from 59 patients with gastrointestinal cancers (consisting of esophageal, gastric, colorectal, biliary, and pancreatic cancers) who visited the outpatient clinic for cancer chemotherapy and palliative care at Iga General Hospital (Iga, Japan) were analyzed. All of the patients underwent palliative chemotherapy (53 patients after surgery, 6 patients who did not undergo surgery) together with the body composition measurement including total body weight, skeletal muscle weight, fat weight, and water weight each time they visited this clinic, which was approximately once a month. All of the patients agreed to provide their clinical data for analyses and their blood for DNA testing after written informed consent. Patients' weight loss was evaluated as a weight loss of $>5 \%$ body weight (WL5) or that of $>10 \%$ body weight (WL10) within 6 months after recruitment (which was equal to the time they underwent surgery or the initial course of chemotherapy). This study was approved by the Institutional Review Board of Nagoya University Graduate School of Medicine (Nagoya, Japan; approval no. 2013-0220-10).

DNA sample preparation and genotyping. DNA was extracted from the buffy coat using the Qiagen DNeasy mini kit (Qiagen, Hilden, Germany). Genotyping for $I L-1 B$ C-31T, $I L-I R N$ VNTR, $I L-6$ C-634G, $I L-8$ T-251A, and $I L-10$ T-819C polymorphisms was conducted using polymerase chain reaction with confronting two-pair primers (PCR-CTPP) (7), and that for the $I L-10$ A-1082G polymorphism was conducted using the ABI PRISM 7300 Real-Time PCR System (Applied Biosystems; Thermo Fisher Scientific, Inc., Waltham, MA, USA). The sequences of the primers used are the same as previously described (8-10).

Statistical analysis. The $\chi^{2}$ test was used to compare the frequencies in the contingency tables. A Kaplan-Meier curve together with the log-rank test and the Cox proportional hazard model were used for the evaluation of survival-time analyses. The unconditional logistic regression model adjusted for sex and age was used to estimate the risk of weight loss. In addition, to evaluate the effect of measured genotypes on body composition of the participating patients, the $\beta$-values for the slope of each body composition element [i.e., the skeletal muscle weight $(\mathrm{kg})$ and extra-cellular water [in proportion to the total body weight)] per allele model, which was the additive model, were calculated using linear regression. All P-values were two-sided, and $\mathrm{P}<0.05$ was considered to indicate a statistically significant difference.
Table I. Characteristics of the study subjects.

\begin{tabular}{|c|c|}
\hline Variables & n (or years) \\
\hline Age [years (sd)] & $69.1(8.4)$ \\
\hline \multicolumn{2}{|l|}{$\operatorname{Sex}[\mathrm{n}(\%)]$} \\
\hline Male & $37(62.7)$ \\
\hline Female & $22(37.3)$ \\
\hline \multicolumn{2}{|c|}{ Cancer type [n (\%)] } \\
\hline Esophageal & $2(3.4)$ \\
\hline Stomach & $11(18.6)$ \\
\hline Colorectal & $40(67.8)$ \\
\hline Pancreatic & $5(8.5)$ \\
\hline Billiary & $1(1.7)$ \\
\hline \multicolumn{2}{|c|}{ UICC stage [n (\%)] } \\
\hline I & $5(8.5)$ \\
\hline II & $10(16.9)$ \\
\hline III & $15(25.4)$ \\
\hline IV & $29(49.2)$ \\
\hline \multicolumn{2}{|c|}{ Genotype frequency } \\
\hline \multicolumn{2}{|c|}{$I L-1 B$ C-31T (rs1143627) } \\
\hline$C / C$ & $17(28.8)$ \\
\hline$C / T$ & $30(50.9)$ \\
\hline$T / T$ & $12(20.3)$ \\
\hline \multicolumn{2}{|l|}{$I L-1 R N$ VNTR } \\
\hline $2 / 2$ & $1(1.7)$ \\
\hline $2 / 5$ & $3(5.1)$ \\
\hline $5 / 5$ & $53(89.8)$ \\
\hline $5 / 6$ & $2(3.4)$ \\
\hline \multicolumn{2}{|c|}{$I L-6$ C-634G (rs 1800796) } \\
\hline$C / C$ & $36(61.0)$ \\
\hline$C / G$ & $20(33.9)$ \\
\hline$G / G$ & $3(5.1)$ \\
\hline \multicolumn{2}{|c|}{$I L-8 \mathrm{~T}-251 \mathrm{~A}(\mathrm{rs} 4073)$} \\
\hline$T / T$ & $23(39.0)$ \\
\hline$A / T$ & $28(47.4)$ \\
\hline$A / A$ & $8(13.6)$ \\
\hline \multicolumn{2}{|c|}{ IL-10 T-819C (rs3021097) } \\
\hline$T / T$ & $26(44.1)$ \\
\hline$C / T$ & $27(45.7)$ \\
\hline$C / C$ & $6(10.2)$ \\
\hline \multicolumn{2}{|c|}{ IL-10 A-1082G (rs1800896) } \\
\hline$A / A$ & $52(88.1)$ \\
\hline$A / G$ & $7(11.9)$ \\
\hline$G / G$ & $0(0.0)$ \\
\hline
\end{tabular}

IL, interleukin; UICC, Union for International Cancer Control.

\section{Results}

Patient characteristics. Patient characteristics are summarized in Table I. A total of 59 patients with gastrointestinal cancers in palliative care participated in the study, in whom 
Table II. Risk of weight loss by cytokine genotype.

\begin{tabular}{|c|c|c|c|c|c|c|c|c|}
\hline Polymorphism & WL5 & WL5 (-) & Crude OR & $\mathrm{aOR}$ & WL10 & WL10 (-) & Crude OR & $\mathrm{aOR}$ \\
\hline \multicolumn{9}{|l|}{$\begin{array}{l}I L-1 B \text { C-31T } \\
(\mathrm{rs} 1143627)\end{array}$} \\
\hline$C / C$ & 11 & 4 & 1 & 1 & 4 & 11 & 1 & 1 \\
\hline$C / T$ & 17 & 9 & $\begin{array}{c}0.69 \\
(0.17-2.79)\end{array}$ & $\begin{array}{c}0.76 \\
(0.18-3.19)\end{array}$ & 11 & 15 & $\begin{array}{c}2.02 \\
(0.51-8.05)\end{array}$ & $\begin{array}{c}2.07 \\
(0.50-8.53)\end{array}$ \\
\hline$T / T$ & 4 & 6 & $\begin{array}{c}0.24 \\
(0.04-1.33)\end{array}$ & $\begin{array}{c}0.20 \\
(0.03-1.19)\end{array}$ & 4 & 6 & $\begin{array}{c}1.83 \\
(0.33-10.10)\end{array}$ & $\begin{array}{c}1.73 \\
(0.31-9.78)\end{array}$ \\
\hline \multicolumn{9}{|l|}{$I L-I R N$ VNTR } \\
\hline$L / L$ & 31 & 17 & 1 & 1 & 18 & 30 & 1 & 1 \\
\hline$L / 2+2 / 2^{\mathrm{a}}$ & 1 & 2 & $\begin{array}{c}0.27 \\
(0.02-3.25)\end{array}$ & $\begin{array}{c}0.27 \\
(0.02-3.29)\end{array}$ & 1 & 2 & $\begin{array}{c}0.83 \\
(0.07-9.86)\end{array}$ & $\begin{array}{c}0.87 \\
(0.07-10.45)\end{array}$ \\
\hline \multicolumn{9}{|l|}{$\begin{array}{l}I L-6 \text { C-634G } \\
(\mathrm{rs} 1800796)\end{array}$} \\
\hline$C / C$ & 19 & 12 & 1 & 1 & 12 & 19 & 1 & 1 \\
\hline$C / G$ & 11 & 6 & $\begin{array}{c}1.16 \\
(0.34-3.96)\end{array}$ & $\begin{array}{c}1.12 \\
(0.32-3.97)\end{array}$ & 5 & 12 & $\begin{array}{c}0.66 \\
(0.19-2.35)\end{array}$ & $\begin{array}{c}0.69 \\
(0.19-2.54)\end{array}$ \\
\hline$G / G$ & 2 & 1 & $\begin{array}{c}1.26 \\
(0.10-15.49)\end{array}$ & $\begin{array}{c}1.11 \\
(0.08-14.89)\end{array}$ & 2 & 1 & $\begin{array}{c}3.17 \\
(0.26-38.84)\end{array}$ & $\begin{array}{c}3.32 \\
(0.25-44.45)\end{array}$ \\
\hline \multicolumn{9}{|c|}{$I L-8 \mathrm{~T}-251 \mathrm{~A}(\mathrm{rs} 4073)$} \\
\hline$T / T$ & 15 & 5 & 1 & 1 & 10 & 10 & 1 & 1 \\
\hline$A / T$ & 14 & 11 & $\begin{array}{c}0.42 \\
(0.12-1.53)\end{array}$ & $\begin{array}{c}0.40 \\
(0.10-1.60)\end{array}$ & 7 & 18 & $\begin{array}{c}0.39 \\
(0.11-1.34)\end{array}$ & $\begin{array}{c}0.30 \\
(0.08-1.20)\end{array}$ \\
\hline$A / A$ & 3 & 3 & $\begin{array}{c}0.33 \\
(0.05-2.21)\end{array}$ & $\begin{array}{c}0.33 \\
(0.05-2.26)\end{array}$ & 2 & 4 & $\begin{array}{c}0.50 \\
(0.07-3.38)\end{array}$ & $\begin{array}{c}0.46 \\
(0.06-3.29)\end{array}$ \\
\hline \multicolumn{9}{|l|}{$\begin{array}{l}I L-10 \mathrm{~T}-819 \mathrm{C} \\
(\mathrm{rs} 3021097)\end{array}$} \\
\hline$T / T$ & 11 & 10 & 1 & 1 & 5 & 16 & 1 & 1 \\
\hline$C / T$ & 19 & 8 & $\begin{array}{c}2.16 \\
(0.66-7.10)\end{array}$ & $\begin{array}{c}2.48 \\
(0.71-8.69)\end{array}$ & 12 & 15 & $\begin{array}{c}2.56 \\
(0.73-9.01)\end{array}$ & $\begin{array}{c}3.24 \\
(0.84-12.43)\end{array}$ \\
\hline$C / C$ & 2 & 1 & $\begin{array}{c}1.82 \\
(0.14-23.25)\end{array}$ & $\begin{array}{c}2.08 \\
(0.15-28.05)\end{array}$ & 2 & 1 & $\begin{array}{c}6.40 \\
(0.47-86.34)\end{array}$ & $\begin{array}{c}8.73 \\
(0.60-127.38) \\
\text { P for trend }=0.046\end{array}$ \\
\hline$C / T+C / C$ & 21 & 9 & $\begin{array}{c}2.12 \\
(0.67-6.76)\end{array}$ & $\begin{array}{c}2.44 \\
(0.72-8.30)\end{array}$ & 14 & 16 & $\begin{array}{c}2.80 \\
(0.82-9.62)\end{array}$ & $\begin{array}{c}3.55 \\
(0.94-13.35) \\
P=0.061\end{array}$ \\
\hline \multicolumn{9}{|l|}{$\begin{array}{l}I L-10 \mathrm{~A}-1082 \mathrm{G} \\
(\mathrm{rs} 1800896)\end{array}$} \\
\hline$A / A$ & 30 & 15 & 1 & 1 & 17 & 28 & 1 & 1 \\
\hline$A / G$ & 2 & 4 & $\begin{array}{c}0.25 \\
(0.04-1.52)\end{array}$ & $\begin{array}{c}0.22 \\
(0.04-1.43)\end{array}$ & 2 & 4 & $\begin{array}{c}0.82 \\
(0.14-4.99)\end{array}$ & $\begin{array}{c}0.75 \\
(0.12-4.65)\end{array}$ \\
\hline
\end{tabular}

WL5 (10), indicates the number of subjects with weight loss more than 5\% (or 10\%); WL5 (10) (-), indicates those with no weight loss; OR,

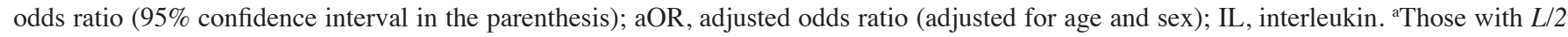
and 2/2 genotypes were combined together because of the small number of the subjects in each stratum. Data for weight loss (body weights at two time-points; baseline and 6 months later) was available in 51 subjects.

colorectal cancer patients $(67.8 \%)$ and patients with Union for International Cancer Control (UICC) clinical stage IV (49.2\%) predominated, and polymorphisms of $I L-1 B$ C-31T, $I L-1 R N$ VNTR, $I L-6$ C-634G, $I L-8$ T-251A, $I L-10$ T-819C and $I L-10$ A-1082G were successfully genotyped for all the patients.
Correlation between cytokine polymorphisms and weight loss. Table II shows the frequency of weight loss stratified by genotype for each cytokine polymorphism. Although a significant increase in the risk of $10 \%$ weight loss (WL10) was observed in patients with an increased number of $C$ alleles with the $I L-10$ $\mathrm{T}-819 \mathrm{C}$ polymorphism (per-allele $\mathrm{OR}=3.09, \mathrm{P}=0.046$, by the 
Table III. Change in body composition by genotypes.

\begin{tabular}{lcccc}
\hline Polymorphism & $\beta$ for the slope of skeletal muscle ${ }^{\mathrm{a}, \mathrm{b}}$ & $\mathrm{P}$ & $\beta$ for the slope of ECW & $\mathrm{P}$ \\
\hline$I L-1 B$ C-31T (rs1143627) & $0.172(-0.100,0.445)$ & 0.211 & $0.0077(-0.0963,0.1116)$ & 0.883 \\
$I L-1 R N$ VNTR & $-0.681(-1.064,-0.299)$ & 0.001 & $0.0208(-0.1385,0.1801)$ & 0.795 \\
$I L-6$ C-634G (rs1800796) & $-0.040(-0.367,0.288)$ & 0.809 & $0.0007(-0.0051,0.0019)$ & 0.245 \\
$I L-8$ T-251A (rs4073) & $-0.175(-0.458,0.107)$ & 0.219 & $0.0059(-0.1019,0.1136)$ & 0.913 \\
$I L-10$ T-819C (rs3021097) & $-0.117(-0.410,0.176)$ & 0.427 & $0.1119(-0.0051,0.2187)$ & 0.040 \\
$I L-10$ A-1082G (rs1800896) & $-0.267(-0.858,0.325)$ & 0.370 & $0.0036(-0.2204,0.2277)$ & 0.974
\end{tabular}

${ }^{a} \beta$-values for the slope of each body composition element per allele (additive) model were calculated using linear regression; ECW, extra-cellular water (in proportion to the total body weight). ${ }^{\text {b} M o n t h l y ~ b o d y ~ c o m p o s i t i o n ~ d a t a ~ w a s ~ a v a i l a b l e ~ i n ~} 58$ subjects.

sex- and age-adjusted additive model), none of the other cytokine polymorphisms showed statistical significance. Additionally, further analyses of change in the body composition by genotype revealed a significant reduction in skeletal muscle weight by the increasing number of the long-repeat $(L)$ alleles of the $I L-I R N$ VNTR polymorphism $(\mathrm{P}=0.001)$. Additionally, there was a significant increase in the weight proportion of extra-cellular water $(\mathrm{ECW})$ with an increasing number of $C$ alleles in the IL-10 T-819C polymorphism ( $\mathrm{P}=0.040$; Table III).

Correlation between cytokine polymorphisms and patients' survival. We analyzed the effect of all cytokine polymorphisms examined on patient survival using the Kaplan-Meier method. Those with at least one $I L-1 R N$ VNTR 2 allele showed significantly worse survival ( $\mathrm{P}=0.010$, logrank test), whereas those with the $I L-6-634 G / G$ genotype showed significantly worse survival $(\mathrm{P}=0.0001)$, as shown in Fig. 1 . Further multivariate analyses using the Cox proportional hazard model revealed that the $I L-10-1082 \mathrm{~A} / \mathrm{G}$ genotype was an independent prognostic factor for overall survival in patients with gastrointestinal cancer, with the adjusted hazard ratio (aHR) of 6.48 (95\% CI: 1.03-40.54, $\mathrm{P}=0.046)$ when adjusted for sex, age, and clinical stage, whereas the aHR for the $I L-1$ RN VNTR [aHR=8.84 (95\% CI: 1.48-52.85, P=0.017) for subjects with 2 allele vs. $L / L$ genotype] and that for the $I L-6$ C-634G [aHR=39.15 (4.25-360.67, P=0.001) for subjects with $G / G$ genotype vs. others] also had significantly elevated aHRs (Table IV). The effects of the $I L-1 R N$ VNTR, $I L-6$ C-634G, and $I L-10$ A-1082G polymorphisms on the survival of patients with colorectal cancer, which is the most frequent type of cancer, were in the same direction as those of all the patients in this study (data not shown).

\section{Discussion}

The present study examined the influence of several cytokine polymorphisms on the clinical outcome of gastrointestinal cancer patients, and revealed that polymorphisms in $I L-I R N$ and $I L-6$ genes have a significant impact on patient survival, based on data obtained from a single institution. The findings obtained were consistent with the previous reports $(11,12)$, which underscored the potential clinical importance of sequence variations of these cytokines in gastrointestinal cancer patients' medical care. $I L-I R N$ encodes the antagonist
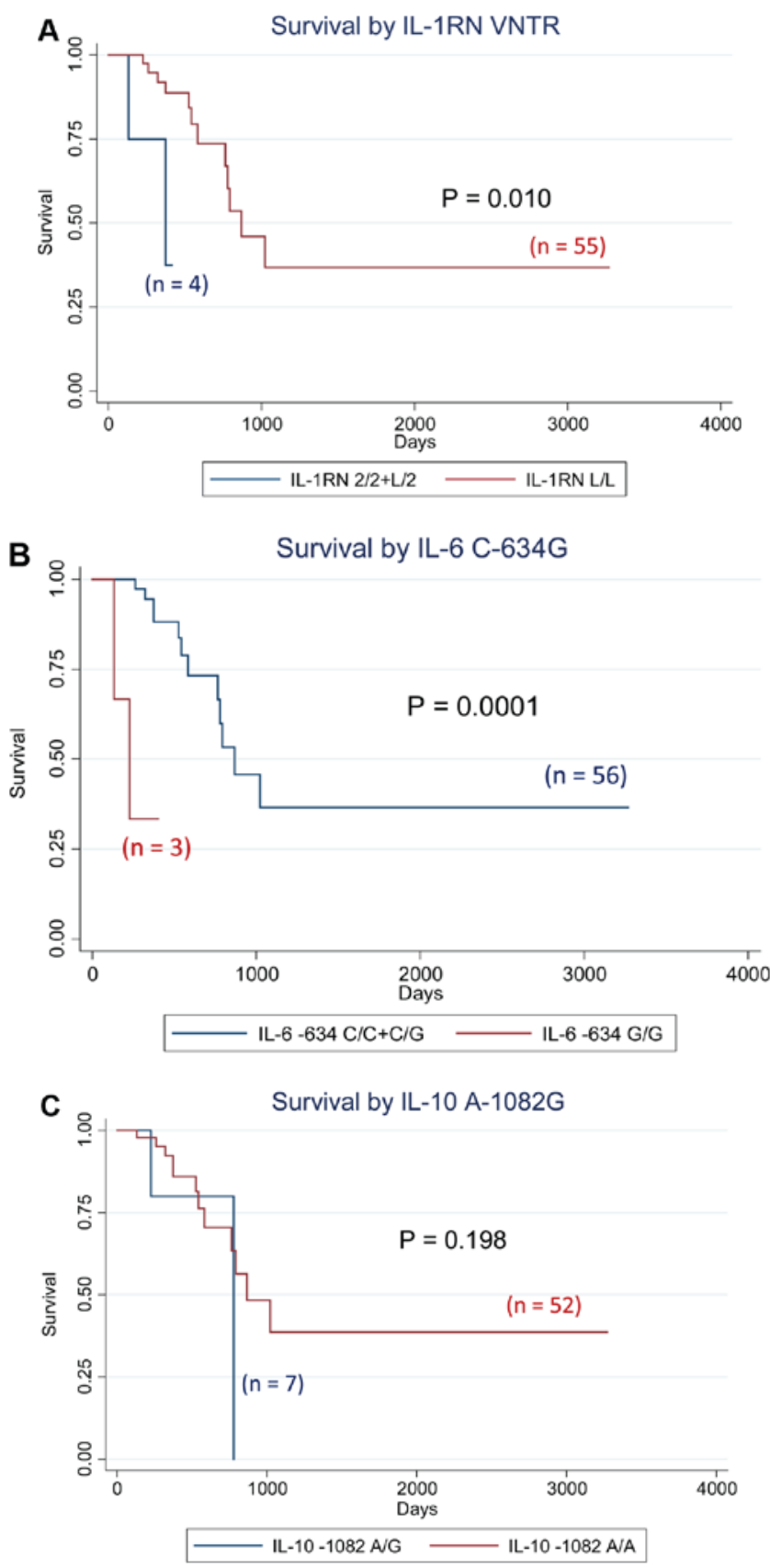

Figure 1. Survival curve by cytokine genotypes. (A) Survival by $I L-1 R N$ VNTR; (B) Survival by $I L-6$ C-634G; (C) Survival by $I L-10$ A-1082G. $\mathrm{P}$-values indicate Log-rank P-values. IL, interleukin. 
Table IV. Patient prognosis by cytokine genotypes.

\begin{tabular}{|c|c|c|c|c|c|c|}
\hline Polymorphism & Comparison groups & $\begin{array}{c}\text { Log-rank } \\
\text { P }\end{array}$ & Model & Crude HR & aHR-1 & aHR-2 \\
\hline \multirow[t]{3}{*}{$I L-1 B$ C-31T (rs1143627) } & All 3 genotypes & 0.916 & Additive & $\begin{array}{c}1.03 \\
(0.53-2.00)\end{array}$ & $\begin{array}{c}0.89 \\
(0.39-2.03)\end{array}$ & $\begin{array}{c}0.74 \\
(0.33-1.65)\end{array}$ \\
\hline & vt. hetero+vt. homo vs. wt. homo & 0.792 & Dominant & $\begin{array}{c}1.16 \\
(0.39-3.44)\end{array}$ & $\begin{array}{c}1.02 \\
(0.29-3.54)\end{array}$ & $\begin{array}{c}0.93 \\
(0.27-3.21)\end{array}$ \\
\hline & vt. homo vs. others & 0.889 & Recessive & $\begin{array}{c}0.91 \\
(0.25-3.30)\end{array}$ & $\begin{array}{c}0.65 \\
(0.14-3.04)\end{array}$ & $\begin{array}{c}0.34 \\
(0.06-1.83)\end{array}$ \\
\hline \multirow[t]{3}{*}{$I L-1 R N \mathrm{VNTR}^{\mathrm{a}}$} & All 3 genotypes & $<0.0001$ & Additive & $\begin{array}{c}8.29 \\
(2.05-33.47)\end{array}$ & $\begin{array}{c}8.28 \\
(2.05-33.51)\end{array}$ & $\begin{array}{c}8.88 \\
(2.07-38.14)\end{array}$ \\
\hline & vt. hetero+vt. homo vs. wt. homo & 0.010 & Dominant & $\begin{array}{c}6.83 \\
(1.25-37.36)\end{array}$ & $\begin{array}{c}6.61 \\
(1.19-36.71)\end{array}$ & $\begin{array}{c}8.84 \\
(1.48-52.85)\end{array}$ \\
\hline & vt. homo vs. others & $<0.0001$ & Recessive & - & - & - \\
\hline \multirow[t]{3}{*}{$I L-6$ C-634G (rs1800796) } & All 3 genotypes & 0.0005 & Additive & $\begin{array}{c}2.61 \\
(1.03-6.58)\end{array}$ & $\begin{array}{c}2.71 \\
(0.99-7.40)\end{array}$ & $\begin{array}{c}3.05 \\
(1.07-8.67)\end{array}$ \\
\hline & vt. hetero+vt. homo vs. wt. homo & 0.206 & Dominant & $\begin{array}{c}1.96 \\
(0.68-5.65)\end{array}$ & $\begin{array}{c}1.92 \\
(0.64-5.73)\end{array}$ & $\begin{array}{c}1.97 \\
(0.66-5.90)\end{array}$ \\
\hline & vt. homo vs. others & 0.0001 & Recessive & $\begin{array}{c}13.31 \\
(2.40-73.84)\end{array}$ & $\begin{array}{c}15.01 \\
(2.22-101.41)\end{array}$ & $\begin{array}{c}39.15 \\
(4.25-360.67)\end{array}$ \\
\hline \multirow[t]{3}{*}{$I L-8 \mathrm{~T}-251 \mathrm{~A}(\mathrm{rs} 4073)$} & All 3 genotypes & 0.869 & Additive & $\begin{array}{c}0.84 \\
(0.37-1.87)\end{array}$ & $\begin{array}{c}0.77 \\
(0.34-1.77)\end{array}$ & $\begin{array}{c}0.97 \\
(0.40-2.39)\end{array}$ \\
\hline & vt. hetero+vt. homo vs. wt. homo & 0.798 & Dominant & $\begin{array}{c}0.87 \\
(0.30-2.50)\end{array}$ & $\begin{array}{c}0.83 \\
(0.29-2.43)\end{array}$ & $\begin{array}{c}0.94 \\
(0.32-2.78)\end{array}$ \\
\hline & vt. homo vs. others & 0.601 & Recessive & $\begin{array}{c}0.58 \\
(0.08-4.49)\end{array}$ & $\begin{array}{c}0.43 \\
(0.05-3.77)\end{array}$ & $\begin{array}{c}1.07 \\
(0.11-10.23)\end{array}$ \\
\hline \multirow[t]{3}{*}{$I L-10 \mathrm{~T}-819 \mathrm{C}(\mathrm{rs} 3021097)$} & All 3 genotypes & 0.541 & Additive & $\begin{array}{c}1.10 \\
(0.52-2.36)\end{array}$ & $\begin{array}{c}1.07 \\
(0.49-2.34)\end{array}$ & $\begin{array}{c}1.06 \\
(0.45-2.50)\end{array}$ \\
\hline & vt. hetero+vt. homo vs. wt. homo & 0.478 & Dominant & $\begin{array}{c}1.49 \\
(0.49-4.47)\end{array}$ & $\begin{array}{c}1.50 \\
(0.48-4.66)\end{array}$ & $\begin{array}{c}1.24 \\
(0.39-4.00)\end{array}$ \\
\hline & $v t$. homo vs. others & 0.578 & Recessive & $\begin{array}{c}0.57 \\
(0.07-4.34)\end{array}$ & $\begin{array}{c}0.50 \\
(0.06-3.96)\end{array}$ & $\begin{array}{c}0.74 \\
(0.09-5.87)\end{array}$ \\
\hline $\begin{array}{l}I L-10 \mathrm{~A}-1082 \mathrm{G} \\
(\mathrm{rs} 1800896)\end{array}$ & $A / G$ vs. $A / A$ & 0.198 & - & $\begin{array}{c}2.66 \\
(0.57-12.50)\end{array}$ & $\begin{array}{c}2.98 \\
(0.60-14.73)\end{array}$ & $\begin{array}{c}6.48 \\
(1.03-40.54)\end{array}$ \\
\hline
\end{tabular}

HR, hazard ratio; aHR, adjusted hazard ratio (aHR-1, adjusted for sex and age; aHR-2, adjusted for age, sex and clinical stage [stage 4]). ${ }^{\mathrm{a} F o r}$ $I L-1 R N$ VNTR, $L / L, L / 2$, and $2 / 2$ genotypes were defined as wt. homo, vt. hetero and $v t$. homo, respectively, where $L$ allele includes 5 - and 6-repeat allele.

against IL- $1 \alpha$ and IL-1 $\beta$, and is well-known to play crucial roles in controlling the balance of various proinflammatory processes such as in central nervous system events in the human brain, in the pathogenesis of skin psoriasis, or in the risk of gastrointestinal cancer (13-15). IL-6 is also known to play key roles in tumor-induced inflammation and various subsequent responses including the acute phase responses leading to elevated CRP levels and tumor growth in gastrointestinal cancer (16).

There is an increasing amount of evidence that genetic factors play major roles in the regulation of cytokine production, such as for IL-1RN and IL-6 $(9,17,18)$. Carriers of the $I L-I R N 2$ polymorphism have been shown to have higher IL-1RN circulating levels than non-carriers $(19,20)$, while some other experimental reports suggest the association of the $I L-1 R N$ polymorphism with the amount of IL-1B production, but the directions of the effect seem inconsistent (7). The $I L-1 R N$ VNTR polymorphism is consisted of two to six tandem repeats of 86-bp conserved sequence, which is located in the putative protein binding sites and thus may influence gene expression $(15,21)$. Considering that the genes for IL-1RN and IL-1B are both located on chromosome 2 q14 within a $360-\mathrm{kb}$ region, it is possible that the genetic variation of $I L-1 R N$ VNTR may affect IL-1B levels through linkage disequilibrium on the genome. The present study could not reproduce the previously reported association of $I L-1 R N$ VNTR 2 allele with a better prognosis in gastrointestinal cancer patients, which might be explained by the modulation of the IL-1B levels that results from the $I L-1 R N$ VNTR polymorphism, or by random error because of the relatively small sample size and disease heterogeneity. The significant trend of reduced skeletal muscle weight associated with a higher number of 
$I L-1 R N$ VNTR $L$ alleles, however, is consistent with a previous report (11), considering the lower IL-1RN circulating levels in $L$ allele carriers and the subsequent exacerbated inflammation induced by IL-1B. For the $I L-6$ polymorphism, the $I L-6-634$ $G$ allele is reported to result in higher plasma IL-6 levels, and is associated with a higher risk of cachexia (12). The finding of a worse prognosis in those with the $I L-6-634$ G/G genotype is consistent with a previous report (12), and is regarded as biologically plausible considering that higher $I L-6$ levels that result from the $I L-6-634 G / G$ genotype may exacerbate systemic inflammation, thereby leading to the worse prognosis in gastrointestinal cancer patients under palliative care. The association of the presence of the $I L-10-819 C$ allele with advanced stages of colorectal cancers, and with possible weight loss and an increase in ECW, may suggest possible important roles of this variation in the $I L-10$ gene in the etiology of colorectal cancer patients. Previous studies have shown that IL-10 exerts its anti-inflammatory effects independent of IL-10R, PIK3, or p70S6 kinase (22). Considering that the $T$ allele of the $I L-10 \mathrm{~T}-819 \mathrm{C}$ polymorphism was associated with a higher IL-10 expression, these associations of the $I L-10-819 C$ allele with possible weight loss in gastrointestinal cancer patients might be explained by the reduced IL-10 expression as a result of this polymorphism (23). The $G$ allele of $I L-10$ A-1082G polymorphism was reportedly associated with worse prognosis in patients with gastrointestinal cancers (24). The $I L-10$ A-1082G polymorphism lies within the promoter region of the $I L-10$ gene, where the $G / G$ genotype of this polymorphism was shown to be associated with increased levels of $I L-10$ production (25). Our results in this study verified the clinical impact of the $I L-10-1082 \mathrm{G}$ allele on gastrointestinal cancer patient prognosis, suggesting the potential prognostic role of this $I L-10$ SNP in gastrointestinal cancer patients receiving palliative care. There also exist several other genetic polymorphisms reportedly associated with the risk of cachexia or weight loss in cancer patients to date, such as those in $P$-selectin (SELP), leptin receptor (LEPR), tumor necrosis factor (TNF), lymphotoxin alpha (LTA) or tumor necrosis factor receptor superfamily member IA (TNFRSF1A) genes, which might possibly have biological interactions with the genes investigated in the present study, and would become potential candidates for future investigations as well $(26,27)$.

With regard to technical aspects, a strength of this study design is the frequent monitoring of the patients with detailed data, such as body composition, body weight, and laboratory data, which was conducted at least once to twice per month. The limitations, however, would be the smaller sample size, which should be increased in follow-up studies. The present study result may also suggest that genetic testing of gastrointestinal patients may be useful for predicting patients' need for supportive care such as nutritional intervention or possible molecular therapies, such as recombinant IL-1RN (11). It has been reported that elevated resting energy expenditure in several types of cancer patients is associated with the presence of a systemic inflammatory response, which may lead to a worse clinical outcomes in patients (25). Nutritional interventions such as administration of eicosapentaenoic acid (EPA) have been shown to be effective in partially controlling the systemic inflammation in these cancer patients (28). To examine this possibility, further studies taking into consideration the efficacy of nutritional interventions based on the genetic information are possible future research directions.

In conclusion, this is the first study that showed genetic polymorphisms can be used to predict gastrointestinal cancer patient survival. We also confirmed the previously reported roles of $I L-R N V N T R$ and $I L-6$ C-634G polymorphisms in predicting survival, suggesting the potential feasibility of genetic testing in gastrointestinal cancer patients with palliative care. The sample size of the present study is limited, and the findings should be verified with larger number of patients, to confirm the possible establishment of personalized palliative care for gastrointestinal cancer patients.

\section{Acknowledgements}

The authors would like to thank Ms. Yoko Mitsuda and Ms. Keiko Shibata (Nagoya University, Nagoya, Japan) for their technical assistance.

\section{Funding}

The present study was supported in part by Grants-in-Aid for Scientific Research from the Japanese Ministry of Education, Culture, Sports, Science and Technology, JSPS KAKENHI Grant Number JP (grant no. 25460745).

\section{Availability of data and materials}

The datasets used and/or analyzed in the present study are available from the corresponding author on reasonable request.

\section{Authors' contributions}

$\mathrm{AH}, \mathrm{YO}, \mathrm{YS}$ and CM contributed to the entire study design, data collection and analyses, and reviewed the final version of the paper critically. YM, KO, KT, RN, YI, HS, HU and MT provided the data from the outpatient clinic to the analysts, provided clinical interpretation of the results, and reviewed the paper critically. SM and AO contributed to the collection of clinical data and genotyping of the patient samples, and reviewed the paper. YT and DCM provided an interpretation of the results from the viewpoint of expert surgical scientists and reviewed the final version of the paper.

\section{Ethical approval and consent to participate}

All of the patients agreed to provide their clinical data for analyses and their blood for DNA testing after written informed consent. This study was approved by the Institutional Review Board of Nagoya University Graduate School of Medicine (approval no. 2013-0220-10).

\section{Patient consent for publication}

All study participants approved the publication of the present study. 


\section{Competing interests}

The authors declare that they have no competing interests.

\section{References}

1. Toiyama Y, Miki C, Inoue Y, Tanaka K, Mohri Y and Kusunoki M: Evaluation of an inflammation-based prognostic score for the identification of patients requiring postoperative adjuvant chemotherapy for stage II colorectal cancer. Exp Ther Med 2: 95-101, 2011.

2. Tan BH and Fearon KC: Cytokine gene polymorphisms and susceptibility to cachexia. Curr Opin Support Palliat Care 4: 243-248, 2010

3. Tan BH, Ross JA, Kaasa S, Skorpen F and Fearon KC; European Palliative Care Research Collaborative: Identification of possible genetic polymorphisms involved in cancer cachexia: A systematic review. J Genet 90: 165-177, 2011.

4. Okugawa Y, Miki C, Toiyama Y, Yasuda H, Yokoe T, Saigusa S, Hiro J, Tanaka K, Inoue Y and Kusunoki M: Loss of tumoral expression of soluble IL-6 receptor is associated with disease progression in colorectal cancer. Br J Cancer 103: 787-795, 2010

5. Toiyama Y,Miki C, Inoue Y, Minobe S, Urano H and Kusunoki M: Loss of tissue expression of interleukin-10 promotes the disease progression of colorectal carcinoma. Surg Today 40: 46-53, 2010

6. Konishi N, Miki C, Yoshida T, Tanaka K, Toiyama Y and Kusunoki M: Interleukin-1 receptor antagonist inhibits the expression of vascular endothelial growth factor in colorectal carcinoma. Oncology 68: 138-145, 2005.

7. Hamajima N, Saito T, Matsuo K, Kozaki K, Takahashi T and Tajima K: Polymerase chain reaction with confronting two-pair primers for polymorphism genotyping. Jpn J Cancer Res 91: $865-868,2000$

8. Hamajima N, Matsuo K, Saito T, Tajima K, Okuma K, Yamao K and Tominaga S: Interleukin 1 polymorphisms, lifestyle factors and Helicobacter pylori infection. Jpn J Cancer Res 92: 383-389, 2001.

9. Suma S, Naito M, Wakai K, Sasakabe T, Hattori Y, Okada R, Kawai S, Hishida A, Morita E, Nakagawa H, et al: Effects of IL6 C-634G polymorphism on tooth loss and their interaction with smoking habits. Oral Dis 21: 807-813, 2015.

10. Hamajima N, Katsuda N, Matsuo K, Saito T, Hirose K, Inoue M, Zaki TT, Tajima K and Tominaga S: High anti-Helicobacter pylori antibody seropositivity associated with the combination of IL-8-251TT and IL-10-819TT genotypes. Helicobacter 8: $105-110,2003$.

11. Graziano F, Ruzzo A, Santini D, Humar B, Tonini G, Catalano V, Berardi R, Pizzagalli F, Arduini F, Bearzi I, et al: Prognostic role of interleukin-1beta gene and interleukin-1 receptor antagonist gene polymorphisms in patients with advanced gastric cancer. J Clin Oncol 23: 2339-2345, 2005

12. Zhang D, Zhou Y, Wu L, Wang S, Zheng H, Yu B and Li J: Association of IL-6 gene polymorphisms with cachexia susceptibility and survival time of patients with pancreatic cancer. Ann Clin Lab Sci 38: 113-119, 2008.

13. Carter DB, Deibel MR Jr, Dunn CJ, Tomich CS, Laborde AL, Slightom JL, Berger AE, Bienkowski MJ, Sun FF, McEwan RN, et al: Purification, cloning, expression and biological characterization of an interleukin-1 receptor antagonist protein. Nature 344: 633-638, 1990 .

14. Arend WP: Interleukin 1 receptor antagonist. A new member of the interleukin 1 family. J Clin Invest 88: 1445-1451, 1991.
15. Xue $\mathrm{H}$, Lin $\mathrm{B}$, Ni $\mathrm{P}, \mathrm{Xu} \mathrm{H}$ and Huang $\mathrm{G}$ : Interleukin-1B and interleukin-1 RN polymorphisms and gastric carcinoma risk: A meta-analysis. J Gastroenterol Hepatol 25: $1604-1617,2010$

16. Fearon KC, Glass DJ and Guttridge DC: Cancer cachexia Mediators, signaling and metabolic pathways. Cell Metab 16: 153-166, 2012.

17. Furuta T, El-Omar EM, Xiao F, Shirai N, Takashima M and Sugimura H: Interleukin 1beta polymorphisms increase risk of hypochlorhydria and atrophic gastritis and reduce risk of duodenal ulcer recurrence in Japan. Gastroenterology 123: 92-105, 2002.

18. Ferrari SL, Ahn-Luong L, Garnero P, Humphries SE and Greenspan SL: Two promoter polymorphisms regulating interleukin-6 gene expression are associated with circulating levels of C-reactive protein and markers of bone resorption in postmenopausal women. J Clin Endocrinol Metab 88: 255-259, 2003.

19. Hurme M and Santtila S: IL-1 receptor antagonist (IL-1Ra) plasma levels are co-ordinately regulated by both IL-1Ra and IL-1beta genes. Eur J Immunol 28: 2598-2602, 1998.

20. Vamvakopoulos J, Green C and Metcalfe S: Genetic control of IL-1beta bioactivity through differential regulation of the IL-1 receptor antagonist. Eur J Immunol 32: 2988-2996, 2002.

21. Vamvakopoulos JE, Taylor CJ, Morris-Stiff GJ, Green C and Metcalfe S: The interleukin-1 receptor antagonist gene: A single-copy variant of the intron 2 variable number tandem repeat (VNTR) polymorphism. Eur J Immunogenet 29: 337-340, 2002.

22. Hamajima N, Katsuda N, Matsuo K, Saito T, Hirose K, Inoue M, Zaki TT, Tajima K and Tominaga S: High anti-Helicobacter pylori antibody seropositivity associated with the combination of IL-8-251TT and IL-10-819TT genotypes. Helicobacter 8: 105-110, 2003.

23. Crawley JB, Williams LM, Mander T, Brennan FM and Foxwell BM: Interleukin-10 stimulation of phosphatidylinositol 3-kinase and p70 S6 kinase is required for the proliferative but not the antiinflammatory effects of the cytokine. J Biol Chem 271: 16357-16362, 1996.

24. Deans DA, Tan BH, Ross JA, Rose-Zerilli M, Wigmore SJ, Howell WM, Grimble RF and Fearon KC: Cancer cachexia is associated with the IL10-1082 gene promoter polymorphism in patients with gastroesophageal malignancy. Am J Clin Nutr 89: 1164-1172, 2009.

25. McMillan DC: An inflammation-based prognostic score and its role in the nutrition-based management of patients with cancer. Proc Nutr Soc 67: 257-262, 2008.

26. Tan BH, Ross JA, Kaasa S, Skorpen F and Fearon KC; European Palliative Care Research Collaborative: Identification of possible genetic polymorphisms involved in cancer cachexia: A systematic review. J Genet 90: 165-177, 2011.

27. Tan BH, Fladvad T, Braun TP, Vigano A, Strasser F, Deans DA, Skipworth RJ, Solheim TS, Damaraju S, Ross JA, et al: P-selectin genotype is associated with the development of cancer cachexia. EMBO Mol Med 4: 462-471, 2012.

28. Ries A, Trottenberg P, Elsner F, Stiel S, Haugen D, Kaasa S and Radbruch L: A systematic review on the role of fish oil for the treatment of cachexia in advanced cancer: An EPCRC cachexia guidelines project. Palliat Med 26: 294-304, 2012. 